The soil extrected yielded 0.4 per cent fatty material, and it is concluded that this amount, unless it occurs as a coating on the surfaces of aggregates, is too low to have any great influence on the degree of soil aggregation. Also, any aggregates so formed would be waterproofed, which would probably limit their value in improving soil productivity.

\section{J. GEOGHEGAN}

Jealott's Hill Research Station, E. R. ARMitage

Imperial Chemical Industries, Ltd. Bracknell, Berkshire.

${ }_{1}$ Geoghegan, M. J., and Brian, R. C., Nature, 158, 837 (1946).

2 Geoghegan, M. J., and Brian, R. C., Biochem. J., 43, 5 (1948).

\section{Dietetic Necrosis of the Liver : the Influence of $\alpha$-Tocopherol}

IN 1935, T. E. Weichselbaum ${ }^{1}$ demonstrated that rats on a diet poor in sulphur-containing amino-acids developed 'hæmorrhages' in the liver. Four years later, Gyorgy and Goldblatt ${ }^{2}$ established that these were, in fact, areas of necrosis, and in 1945 Glynn, Himsworth and Neuberger ${ }^{3}$ showed that the factor in protein, lack of which caused such necrosis, was cystine. But since that time it has become clear that, even when similar diets are used, there are surprising discrepancies between the results obtained in different laboratories; some investigators producing the lesion regularly, others occasionally, and some not at all 4 . In view of the fact that much work is being started in this field, it may be useful to make known without delay the results of a pilot experiment which seems to throw some light on these discrepancies.

In 1944, Schwartz ${ }^{5}$ produced a necrosis of the liver in rats by means of a diet containing as much as 15 per cent of an alkali-treated casein, but observed no lesions when crude casein was used. This lesion was prevented by wheat germ oil, and later the protective factor was shown to be tocopherol. Owing to the War, Schwartz's results remained unknown until very recently and, quite independently, Paul Gyorgy of Philadelphia ${ }^{6}$ produced evidence pointing to a similar conclusion. Searching for an explanation of the irregularity with which his diets produced liver necrosis, he noted a relationship between the incidence of the lesion and the type of dietary fat and, later, correlated this with the tocopherol content of the fat. $\mathrm{He}$ then showed that the incidence of liver necrosis in animals receiving diets deficient in sulphurcontaining amino-acids was decreased by giving supplements of tocopherol, although adequate dietary cystine prevented the lesion even when the supply of tocopherol was deficient.

On learning of Gyorgy's results, we placed two groups of rats on the yeast protein diet which we had found most effective in producing massive hepatic necrosis. One group was given a supplement of $15-20$ mgm. of $\alpha$-tocopherol twice a week; the other received none. All the eleven animals which did not receive tocopherol showed massive hepatic necrosis or its sequel, post-necrotic scarring; only one of the eight animals receiving the supplement showed any trace of liver damage. We then communicated with the workers in Great Britain who had failed to produce necrosis by diets stated to be identical with ours. In each case we found that tocopherol had been added to the vitamin supplements we had prescribed, under the impression that we had forgotten to mention it in our communications. One investiga- tor, thereupon, repeated his experiments, omitting the tocopherol supplement, and produced necrosis for the first time in his experience.

But these results did not entirely resolve the discrepancies. Over the last two years we were form. ing the impression that, while we were still able to produce the lesion in all animals, it was taking longer to do so, and, further, the lesion tended to be milder. Again, in other laboratories, even when tocopherol was omitted from the diet, the incidence-rate of necrosis was rarely more than 30 per cent as compared with the 100 per cent in our laboratory. On considering these points, it occurred to us that there were strong indications that the body held tenaciously to its tocopherol stores and that, in consequence, the nature of the pre-experimental diet might be of importance to the success of the experiment. Accordingly, we took two groups of rats on weaning and put both on a diet calculated to produce tocopherol deficiency, but supplemented the diet of one group with tocopherol. After 110 days on these diets, both groups were placed on the diet low in sulphur-containing amino-acids and tocopherol which had proved effective in producing liver necrosis. At the time of writing, 104 days after starting the necrogenic diet, eight of the eleven animals which did not receive supplements of tocopherol in the pre-experimental diet are dead of necrosis; the eight rats which did are alive and well.

We do not claim that these findings completely explain the discrepancies between the results from different laboratories. What we do suggest is that investigators planning experiments on dietetic massive necrosis of the liver should pay attention to the diet eaten by their animals in the pre-experimental period, and to ensure that it is not rich in tocopherol.

\section{H. P. HIMSWORTH}

O. LINDAN

University College Hospital Medical School, University Street, London, W.C.1. Sept. 21.

${ }^{1}$ Weichselbaum, T. E., Quart. J. Exp. Physiol., 25, 363 (1935). Gyorgy, P., and Goldblatt, H., J. Exp. Med., 70, 185 (1939). Glynn, L. E., Himsworth, H. P., and Neuberger, A., Brit. J. Exp. Path., 26, 326 (1945).

- Radakrishna Rao, M. V., Nature, 161, 446 (1948).

s Schwartz, K., Z. physiol. Chem., 281, 101, 109 (1944).

"Gyorgy, P., 6th Conf. on Liver Injury, Josiah Macy, Jr., Foundation Report, 67 (New York, 1947).

\section{Two New Cardiac Glycosides, Rubellin and Transvaalin, from South African Species of Urginea}

THE isolation of rubellin from Urginea rubella by me was mentioned by Sapeika1. Compared with ouabain, standard strophanthidin B.P. 1932, lanatoside $\mathrm{C}$, digoxin, and digitoxin, rubellin is the most active glycoside ${ }^{2}$.

The glycoside was prepared in $0.015-0.045$ per cent yield by shaking out concentrated aqueous extracts of the bulb with ethyl acetate. On concentration of the ethyl acetate extracts, the glycoside crystallizes spontaneously. Rubellin has melting point $261-263^{\circ} \mathrm{C}$. and $[\alpha]_{D}{ }^{27}=15.81$ (methyl al. cohol).

Analysis. $\mathrm{C}=59 \cdot 06,59 \cdot 09,58 \cdot 95,58 \cdot 65$ per cent. H $=6.55,6 \cdot 64,6 \cdot 43,6 \cdot 43$ per cent. Calculated for $\mathrm{C}_{88} \mathrm{H}_{48} \mathrm{O}_{18}: \mathrm{C}=58.69, \mathrm{H}=6.56$ per cent. Mol. wt. = $736 \cdot 7$. 